\title{
RBF MODEL FOR THE MASS LOSS OF A BRASS IN CAVITATION FIELD
}

\author{
Alina BĂRBULESCU, Cristian Ștefan DUMITRIU \\ Transilvania University of Brasov, Romania \\ e-mail: alina.barbulescu@unitbv.ro, cristian.dumitriu@unitbv.ro
}

\begin{abstract}
This article aims at presenting the model of the mass loss of a brass sample in ultrasonic cavitation field in saline water. The experiments done for data collecting was performed in three scenarios. In the first one, the high frequency generator worked at three power levels - $80 \mathrm{~W}$, at the second one - at $120 \mathrm{~W}$, and in the third one - at $180 \mathrm{~W}$. The Model has been built using the series of the mass loss on surface.
\end{abstract}

KEYWORDS: brass, cavitation, mass loss, mathematical model

\section{Introduction}

Ultrasound cavitation is the process of formation, growth, and collapse of vapors bubbles inside a liquid traversed by an ultrasonic field [1]. High energies appear during this process, resulting in vibrations, noise, erosion-corrosion, unpassivation, sonoluminescence, emulsification etc. [2-3]. The phenomenon is characterized by the liquid discontinuity state when the pressure drop happens under critical values [4]. The cycle collapse/rebound induces a voltage at the cavitation zone boundaries [5-7].

Due to the practical implications of the negative effect of cavitation on the machines and their components working in such conditions, the attach type on materials with different compositions and the mass loss process became a topic of interest for scientists [8-14]. For example, Basumatary et al. [8] analysed the erosion-corrosion mechanism of ships propellers. Petkovsek and Dular [9] observed the cavitation erosion and structures. Wharton and Stokes investigated the corrosion mechanism of some Nickel-Aluminum bronzes, whereas Schüssler and Exner [11] studied the mass loss of the same type of materials in seawater. Other authors [12-14] modelled electrical signals that appeared in the cavitation field in different liquids and the mass loss of different materials in such conditions.

The present article is in line with the previous research investigating the mass loss of copper-based alloys in seawater and modelled the trend of this process [13-14]. The novelty consists of proposing an RBF model that fits the mass loss of a brass (utilized in the shipbuilding industry) in the ultrasound cavitation field.

\section{Materials and methods}

The studied material is a brass, with $57.95 \% \mathrm{Cu}$, $38.45 \% \mathrm{Zn}$, and $2.75 \% \mathrm{~Pb}$.

The of the seawater composition used for all the experiments is the following: salinity: $22.17 \mathrm{~g} / \mathrm{L}$ $\mathrm{NaCl}, 0.31 \mathrm{~g} / \mathrm{L} \mathrm{SO}_{4}{ }^{2-}, \mathrm{pH}=7,6.27 \mathrm{meq} / \mathrm{L}$ - total water hardness, $0.051 \mathrm{mg} / \mathrm{L} \mathrm{Fe}, 0.0033 \mathrm{mg} / \mathrm{L} \mathrm{Ni}$.

The setup utilized for the experiment is shown in Fig. 1 [5, 14]. Its main parts are:

The tank containing the liquid (1); $\mathrm{kHz}(8)$

- The high-frequency generator, working at 20

- The ceramic transducer (7) that is excited by the generator (8);

- A cooling fan (11) utilized for keeping the liquid's temperature constant. The experiment has been performed at $20^{\circ} \mathrm{C}$;

- The command block (12) used for selecting different powers for the generator regime $(80 \mathrm{~W}, 120$ $\mathrm{W}$, or $180 \mathrm{~W}$ ).

The samples were kept in saline water under cavitation produced by ultrasound for a total of 1320 minutes (380 minutes at $80 \mathrm{~W}, 480$ minutes at $120 \mathrm{~W}$, and 480 minutes at $180 \mathrm{~W}$ ) and weighted every 20 minutes.

Based on the measured mass loss values, the variations of the ratios between the absolute mass loss (i.e., the difference between the mass at the moment $t$ and the mass at the beginning of the experiment) on surface have been computed. To test if these values 
come from the same distribution, the Kruskal-Wallis test [15] was performed at the significance level of 0.05 .
The last step was to put together the three data series and determine a Radial Basis Function (RBF) model of the mass loss per surface.

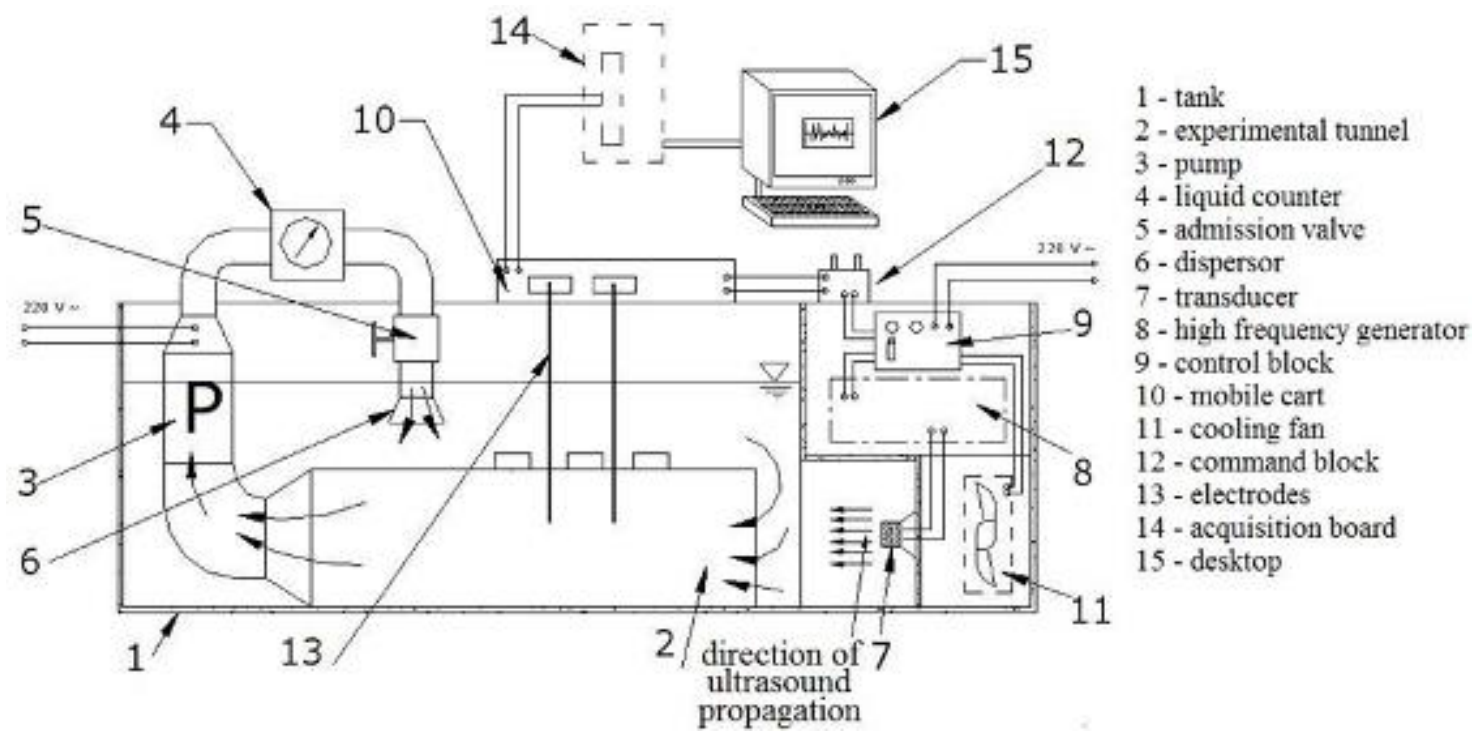

Fig. 1. The experimental setup

Artificial Neural Networks (ANNs) were firstly introduced for modelling the human brain structure and have been developed to understand the brain functioning (direction 1) and to the concept adaptation for using the computational capabilities in solving practical problems (direction 2) [16].

Nowadays, ANNs are widely used for modelling data from various domains where classical modelling methods do not provide satisfactory results, data series present high variability, or do not satisfy the hypotheses necessary to apply classical methods.
ANNs have proved to have good approximation capabilities [17], thus they are employed to find answers to various classification, regression, and forecasting problems [18-24].

An ANNs is built of interconnected layers formed by neurons connected each to the others. There is an input layer, one or many hidden layers, and an output layer. Two classes of ANNs are known recurrent and feed-forward neural networks [25]. RBF networks (RBFNs) belong to the last class and have only a hidden layer.

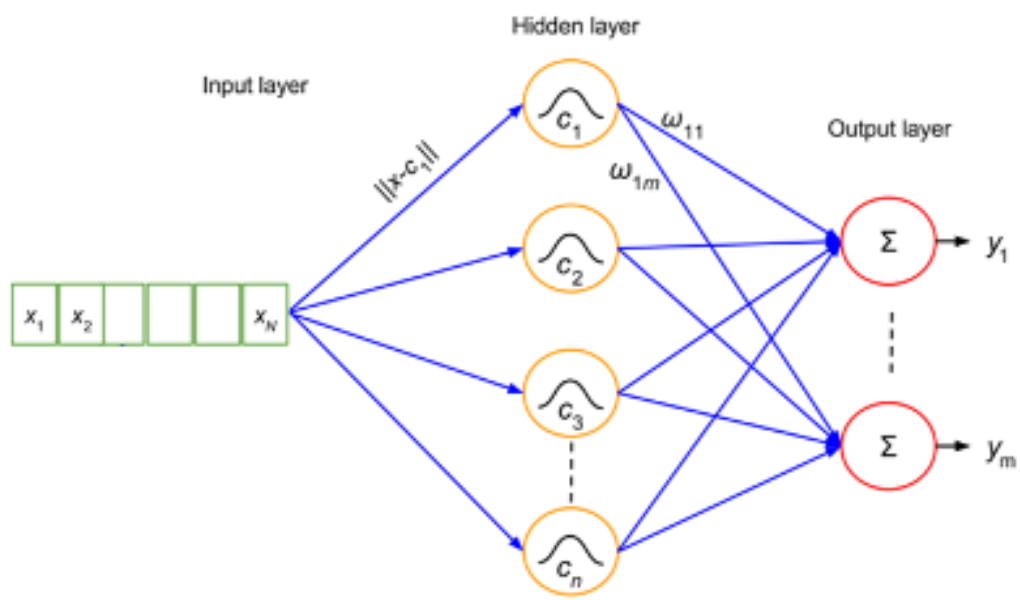

Fig. 2. RBF neural network [26]

ANNs are formed by artificial neurons that process the information that enters the network applying an activation function. The result is then transferred to the next layer. 
The nodes in RBF network's hidden layer transform the input variables, using a radial basis function. The most used is the Gaussian function since no significant improvement of the modelling results was reported when employing other functions. The last layer acts as a summation unit.

The typical structure of an RBF neural network can be seen in Fig. 2.

The output of a hidden unit is $e^{-\left(\left\|x-c_{i}\right\| / b_{i}\right)^{2}}$ in case of a Gaussian kernel function, where $\left\|x-c_{i}\right\|$ is the Euclidian distance between $x$ (the input vector) and the RBF's centroid, $c_{i}$, and $b_{i}$ is the kernel width.

The hidden layer's output, $o_{i}$, are given by:

$$
y_{i}=\sum_{j} w_{i j} o_{j}(x)
$$

where $w_{i j}$ are the weights of the links of the hidden layer $j$ and the output layer, $i$.

At the network initialization, the centroid positions are chosen, whereas the weights and widths result from the network training (which is done by back-propagation).

In this case, the k-means clustering is employed to determine the centroids. An evolutionary algorithm [27] is utilized for selecting the optimum centroids and spread for each neuron and the moment when enough neurons are added to the network (based on the Leave-one-out procedure). The weights optimization is realized by ridge regression, and for minimizing the generalized cross-validation (GCV) error, the algorithm proposed by Orr [28] is utilized.

For details on this kind of network, the readers may see [29-30].

The following settings have been used in our study: the maximum number of neurons -100; population size - 200, the maximum number of generations -20 , maximum generations flat -5 , absolute tolerance $-10 \mathrm{E}-6$, minimum radius -0.01 , maximum radius -400 . The optimal regularization Lambda parameter [28] varies between 0.001, and 10 .

To validate the modeling results, the proportion of variance explained by model $\left(\mathrm{R}^{2}\right)$, the mean absolute error (MAE), the mean standard error (MSE), mean absolute percentage error (MAPE), the correlation between the actual and predicted values $\left(r_{\text {ap }}\right)$ were employed.

\section{Results and discussion}

Let us denote by:

- $t$ - the time,

- $m_{t}$ - the sample mass at the moment $t$,

- $\mathrm{R}^{2}$ - the determination coefficient,

- $s$ - the standard deviation of the residuals in the linear models,

- $S$ - the sample's surface.
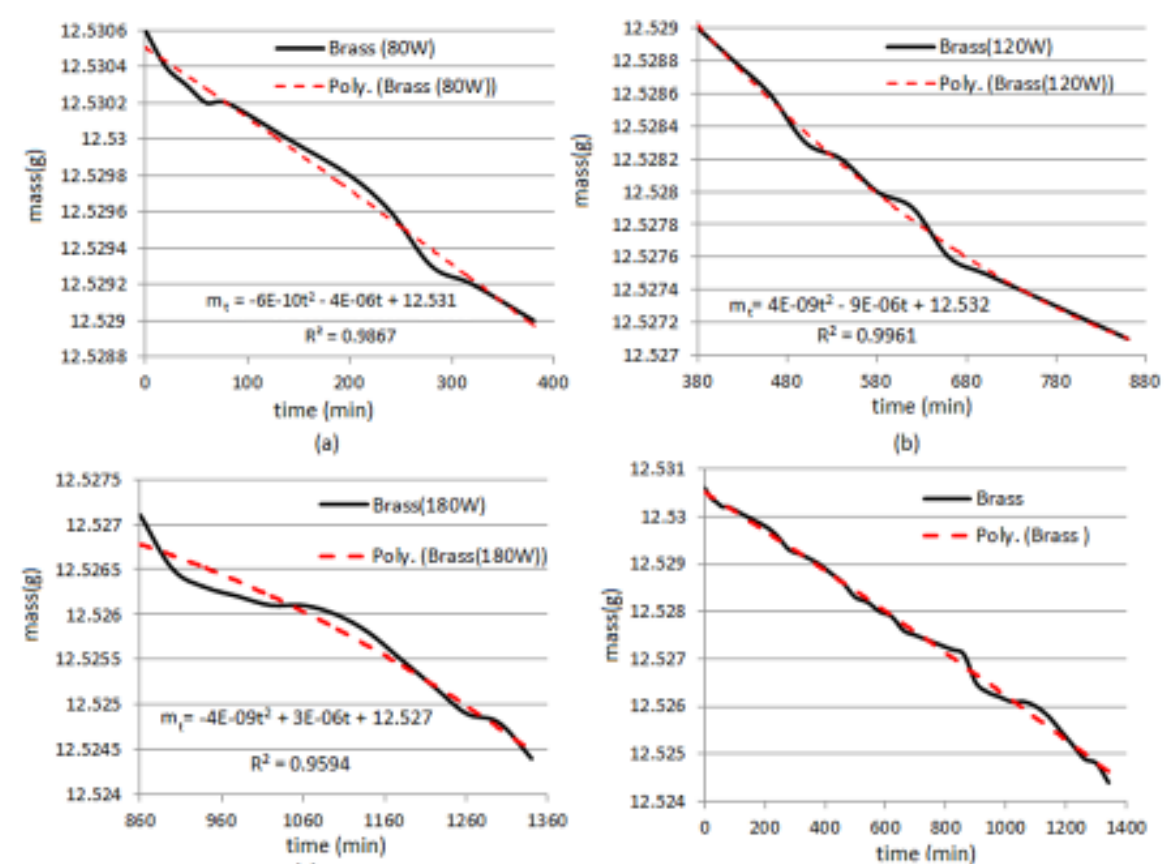

(c) (b)

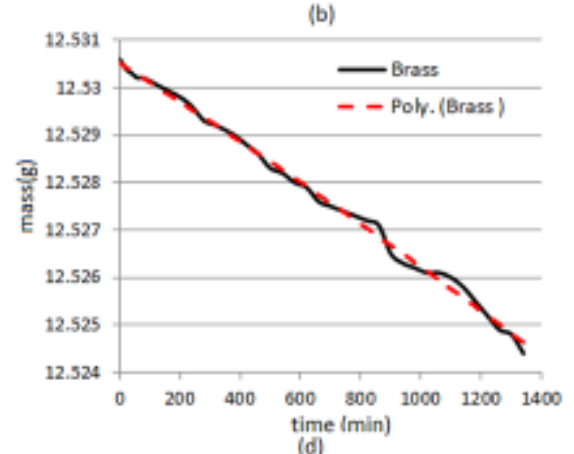

(d)

Fig. 3. The brass mass variation: (a) at $80 \mathrm{~W},(\mathrm{~b})$ at $120 \mathrm{~W},(\mathrm{c})$ at $180 \mathrm{~W},(\mathrm{~d})$ during the entire experiment. The continuous line represents the recorded data and the dotted ones the fitted trend 


\section{THE ANNALS OF “DUNAREA DE JOS” UNIVERSITY OF GALATI \\ FASCICLE IX. METALLURGY AND MATERIALS SCIENCE \\ No. 4 - 2021, ISSN 2668-4748; e-ISSN 2668-4756 \\ Article DOI: https://doi.org/10.35219/mms.2021.4.03}

Figures 3 (a)-(c) show the evolution of the sample mass in time and the fitted trends, which are second-degree polynomials. Figure 3 (d) presents the overall evolution of the sample's mass in time. In all cases, $\mathrm{R}^{2}$ is above 0.95 , and the residual standard deviations are lower than 0.0001 , emphasizing a good data fit.

The evolution of the absolute mass loss per surface at all the power stages is represented in Fig. 4, where the vertical lines delimitate the stages (I-80 W, II-120 W, III-180 W).

The Kruskal - Wallis did not reject the null hypotheses therefore, we built the RBF network. Two-third of the data has been used for training, and for the test, the last third. The parameters found after running the algorithm are:

- $\quad$ Number of neurons $=4$

- $\quad$ Minimum radius $=0.01$

- $\quad$ Maximum radius $=5.88084$

- $\quad$ Minimum Lambda $=0.83554$

- $\quad$ Maximum Lambda $=5.66617$

- Regularization Lambda for final weights = $2.4643 \mathrm{e}-003$ after 7 iterations.

The goodness of fit indicators is presented in Table 1, showing an excellent fit of the data series. The chart of actual versus predicted values confirms this assertion (Fig. 5).

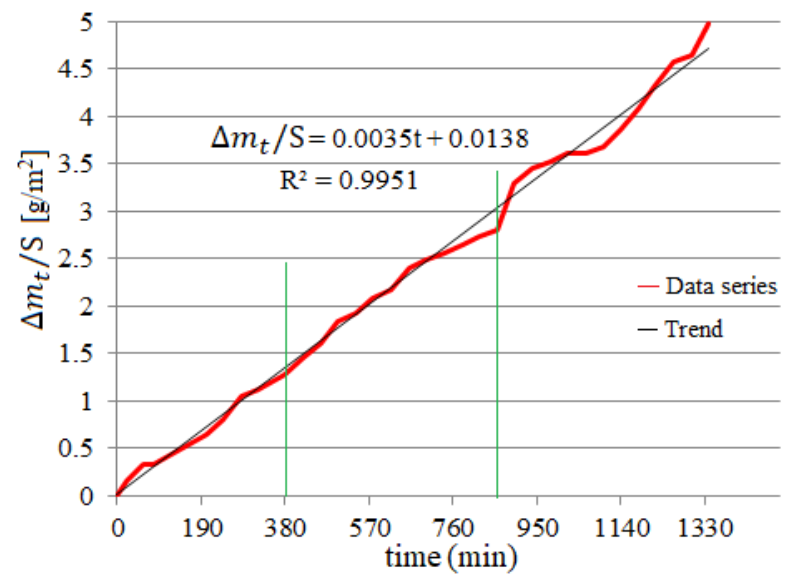

Fig. 4. The absolute mass variation per surface. The vertical lines delimitate the stages (I-80 W, II$120 \mathrm{~W}, \mathrm{III}-180 \mathrm{~W})$

Table 1. Goodness of fit indicators

\begin{tabular}{lcc}
\hline & Training & Test \\
\hline $\mathrm{R}^{2}(\%)$ & 99.463 & 94.898 \\
$\mathrm{MSE}$ & 0.0047 & 0.0125 \\
$\mathrm{MAE}$ & 0.0582 & 0.0943 \\
$\mathrm{MAPE}$ & 9.1388 & 2.3057 \\
$r_{a p}$ & 0.9973 & 0.9799 \\
\hline
\end{tabular}

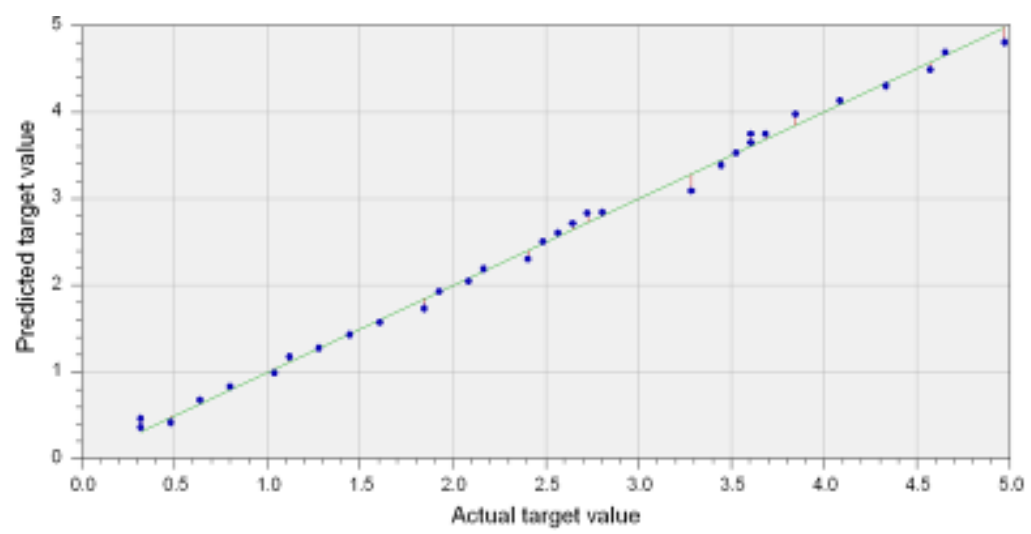

Fig. 5. The predicted values versus the actual target values 


\section{Conclusion}

This article presented the results of mass loss of a brass in ultrasound cavitation field in seawater. The main result is modeling the mass variation per surface in time. The estimation of the RBF model built has been done using five indicators. On both training and test set, $\mathrm{R}^{2}$, and $r_{a p}$ are very close to 1 , showing a good fit of the initial series. MSE and MAPE are smaller on the training set, meaning that the algorithm performs the best on this set. Point of view of MAPE, the best performance is that obtained on the test set.

Overall, the model describes very well the process evolution.

\section{References}

[1]. Flynn H. G., Physics of acoustic cavitation in liquids, Physical Acoustics, vol. 1, Part B, W. P. Mason, Ed. New York: Academic Press, p. 57-172, 1964.

[2]. Young F. E., Cavitation, Mac Graw-Hill, Maidenhead, UK, New York, 1989.

[3]. Rooney J. A., Ultrasound: its Chemical, Physical and Biological Effects, Suslick, VCH, New York, USA 1988.

[4]. Bai L., Yan J., Zeng Z., Ma Y., Cavitation in thin liquid layer: A review, Ultrason. Sonochem., vol. 66, 105092, 2020.

[5]. Bărbulescu A., Marza V., Dumitriu C. S., Patent no RO 123086-B1 (30.09.2010) Installation and method for measuring and determining the effects produced by cavitation in ultrasound field in stationary and circulating media, 2010.

[6]. Bărbulescu A., Models of the voltage induced by cavitation in hydrocarbons, Acta Phys. Pol. B, vol. 37 (10), p. 2919-2931, 2006.

[7]. Bărbulescu A., Dumitriu C. S., Mathematical aspects of the study of the cavitation in liquids, Mathematical Modelling of Environmental and Life Sciences, S. Ion, G. Marinoschi and C. Popa, Eds. București: Editura Academiei Române, p. 7-14, 2006. [8]. Basumatary J., Nie M., Wood J. K., The synergistic effects of cavitation erosion-corrosion in ship propeller materials, J. BioTribo-corros., 1, p. 1-12, 2015.

[9]. Petkovsek M., Dular M., Simultaneous observation of cavitation structures and cavitation erosion, Wear, vol. 300, p. 5564, 2013.

[10]. Wharton J. A., Stokes K. R., The influence of nickelaluminium bronze microstructure and crevice solution on the initiation of crevice corrosion, Electrochim. Acta, 53 (5), p. 24632473, 2008.

[11]. Schüssler A., Exner H. E., The corrosion of nickelaluminium bronzes in seawater-I. Protective layer formation and the passivation mechanism, Corros. Sci., 3 (11), p. 1793-1802, 1993.

[12]. Fortes-Patella R., Choffat T., Reboud J. L., Archer A., Mass loss simulation in cavitation erosion: fatigue criterion approach, Wear, vol. 300, p. 205-215, 2013.
[13]. Bărbulescu A., Dumitriu C. S., Models of the mass loss of some copper alloys, Chem. Bull. Politehnica University (Timişoara), vol. 52 (66), 1-2, p. 120-123, 2007.

[14]. Dumitriu C. S., Bărbulescu A., Studies about the copper base alloys used in naval constructions - modeling the loss mass in different media, Sitech, Craiova, 2007.

[15]. Kruskal W. H., Wallis W. A., Use of ranks in one-criterion variance analysis, J. Am. Stat. Assoc., vol. 47 (260), p. 583-621, 1952.

[16]. Vandeginste B. G. M., Massart D. L., Buydens L. M. C., De Jong S., Lewi P. J., Smeyers-Verbeke J., Artificial Neural Networks. Handbook of Chemometrics and Qualimetrics: Part B, p. 649-699, doi:10.1016/s0922-3487(98)80054-3, 1998.

[17]. Hornik K., Stinchcombe M., White H., Multilayer feedforward networks are universal approximators. Neural Networ, vol. 2 (5), p. 359-366, 1989.

[18]. Bărbulescu A., Dani A., Statistical analysis and classification of the water parameters of Beas River (India), Rom. Rep. Phys., vol. 71, no. 4, art.716, 2019.

[19]. Bărbulescu A., Dumitriu C. S., On the Connection between the GEP Performances and the Time Series Properties, Mathematics, 9 (16), 1853, 2021.

[20]. Bărbulescu A., Dumitriu C. S., Artificial intelligence models for financial time series, Ovidius University Annals, Economic Sciences Series, vol. XXI, Issue 1, p. 685-690, 2021.

[21]. Bărbulescu A., Șerban C., Caramihai S., Assessing the soil pollution using a genetic algorithm, Rom. J. Phys., vol. 66 (3-4), 80, 2021.

[22]. Jia W., Zhao Ding D. L., An optimized RBF neural network algorithm based on partial least squares and genetic algorithm for classification of small sample, Appl. Soft Comput., vol. 48, p. 373384, 2016.

[23]. Meng K., Dong Z. Y. Wang D. H., Wong K. P., A selfadaptive RBF neural network classifier for transformer fault analysis, IEEE Trans. Power Syst., vol. 25 (3), p. 1350-1360, 2010. [24]. Sheta A. F., De Jong K., Time-series forecasting using GAtuned radial basis functions, Inform. Sci., vol. 133 (3), p. 221-228, 2001.

[25]. Al-Mahasneh A. J., Anavatti S., Garratt M., Pratama M., Applications of General Regression Neural Networks, Dynamic Systems, Digital Systems, Asadpour, V. Ed., IntechOpen, DOI: 10.5772/intechopen.80258, 2018.

[26]. Faris H., Aljarah I., Mirjalili S., Evolving Radial Basis Function Networks using moth-flame optimizer, Handbook of Neural Computation, p. 537-550, 2017.

[27]. Chen S., Hong X., Harris C. J., Orthogonal Forward Selection for Constructing the Radial Basis Function Network with Tunable Nodes, Available at: https://eprints.soton.ac.uk/ 261028/1/36440777.pdf, 2005.

[28]. Orr M. J. L., Optimizing the widths of radial basis functions, Proceedings of the $5^{\text {th }}$ Brazilian Symposium on Neural Networks (Cat. No.98EX209), p. 26-29, doi: 10.1109/SBRN. 1998.730989, 1998.

[29]. Park J., Sandberg I. W., Universal approximation using radial basis function networks, Neural Comput., vol.3, p. 246-257, 1991.

[30]. Moody J., Darken C. J., Fast learning in networks of locally-tuned processing units, Neural Comput., vol. 1, p. 281-294, 1989. 